\title{
Kreolisasi dalam Kultur Suporter Sepakbola (Mimikri, Hibriditas dan Glokalisasi Brigata Curva Sud PSS Sleman)
}

\author{
Ade Tri Kusuma \\ Program Studi Ilmu Komunikasi FPSB UII
}

\begin{abstract}
Abtrak
Penelitian ini dilakukan pada kelompok pendukung Brigata Curva Sud PSS Sleman dan juga beberapa komunitas seperti Campus Boys, dan Komunitas Aliansi Utara dengan menggunakan perspektif poskolonial. Penelitian ini menggunakan pendekatan kualitatif dengan tujuan untuk menemukan data sebanyak mungkin dan juga untuk mendapatkan informasi terbaik dari orang yang diwawancarai. Metode penggalian data yang digunakan dalam penelitian ini adalah observasi, wawancara, dokumentasi, dan pelacakan data secara daring. Studi ini menemukan bahwa proses produksi suporter Ultras oleh Brigata Curva Sud PSS Sleman melalui dua cara, media baru dan komunitas pendukung. Dari perspektif poskolonial, penelitian ini menemukan tiga bentuk imitasi Brigata Curva Sud PSS Sleman. Pertama, imitasi yang berubah menjadi Mimikri yang menyebabkan mereka dihina oleh komunitas pendukung lainnya. Kedua, proses marging 2 budaya dari budaya pendukung sepakbola dan penonton metal dan hardcore yang menciptakan budaya baru yang disebut Hibridity. Ketiga, adalah pembentukan budaya yang disebut Kreolisasi, yang dihasilkan dari budaya asing namun tidak melepaskan makna yang asli yang terkandung di dalamnya.
\end{abstract}

\begin{abstract}
This research was conducted on the supporters group of Brigata Curva Sud PSS Sleman and also some communities such as Campus Boys, and North Alliance Community using poskolonial perspective. This study use Qualitative approach with the aim to find as much data as possible and also to get the best possible information from interviewees. Data research methods applied in this research are observation, interview, documentation and online data tracking. This study found that the proces of the in troduction of Ultras Supporters by Brigata Curva Sud PSS Sleman are through two ways, new media and supporters community. From the postcolonial perspective, this study found three forms of imitation Brigata Curva Sud PSS Sleman. First, imitation that turned into Mimicry that cause them being insulteed by other supporters community. Second, the process of marging 2 cultures from the football supporters cultures and the metal and hardcore spectators that creates new cultures called Hibridity. Third, is the establishment of a culture called Kreolisasi, resulting from the foreign culture but don't release the meaning of the original contained in it.
\end{abstract}

Keywords: New Media, Supporter, Brigata Curva Sud PSS Sleman, Mimicry, Hybridtas, Kreolisasi. 


\section{Pendahuluan}

Perkembangan teknologi digital menghasilkan teknologi baru yang banyak berkembang di dalam masyarakat. Salah satu perkembangan teknologi tersebut adalah media baru. Media baru sendiri adalah evolusi dari media lama yang berubah menjadi digital. Salah satu contoh perkembangan media baru adalah dengan mulai banyaknya muncul sosial media yang saat ini sudah sangat akrab digunakan seperti Google, Facebook, Twitter, Youtube, Blog, atau Vlog.

Kehadirnya media baru juga bermanfaat dalam perkembangan dunia sepakbola di Indonesia karena membuat arus informasi tentang dunia sepakbola semakin cepat, dan mudah diterima dimana pun.

Perkembangan media baru, di sisi lain, membuat banyak bermunculan portal berita online seperti web atau sosial media yang banyak meng-update berita dan informasi tentang sepakbola di dunia. Menurut lembaga riset $e$-Marketer, jumlah netizen di Indonesia saat ini mencapai angka 83,7 juta orang pada 2014. Pada 2017, e-Marker memperkirakan netter Indonesia akan mencapai angka 112 juta orang. Hal ini bisa melebihi Jepang diperingkat ke-5 yang jumlah netter-nya tumbuh jauh lebih lamban. Diperkirakan, pada 2018, di dunia, netter akan berjumlah 3,6 miliar yang mengakses internet paling sedikit sekali dalam sebulan. ${ }^{1}$

\footnotetext{
1“ https://kominfo.go.id/content/detail/4286/pe
} ngguna-internet-indonesia-nomor-enam-
Indonesia memiliki banyak supporter yang fanatik, dan juga loyal kepada tim yang di dukungnya seperti Mitra Kukar yang memiliki suppoter Kukar mania, Persib Bandung memiliki supporter Viking, dan Persebaya memiliki supporter Bonek. Perkembangan dunia supporter di Indonesia tersebut tidak bisa dilepaskan oleh perkembangan internet di Indonesia. Seperti ditegaskan Giulianotti dan Robertson (2004), internet memegang peranan penting dalam proses perkembangan globalisasi supporter sepakbola yang ada di dunia, internet mampu memberikan satu gagasan dari setiap masing-masing kelompok supporter sepakbola, dan pembentuk identitas kolektif supporter, konsep dari proses globalisasi.

Dalam perkembangannya, Supporter di Indonesia mempunyai ciri khas masing-masing dalam mendukung tim kesayangan mereka. Dilihat dari 5 tahun belakangan, muncul suatu paham dan fenomena baru di dunia supporter Indonesia. Paham ini sebenarnya bukan paham baru, tapi telah pula berkembang di dunia. Namun, di dunia supporter Indonesia paham ini menjadi warna baru tersendiri. Supporter Indonesia saat ini sedang berkiblat gaya suppoter di Eropa barat dan juga Eropa Timur.

Pada awalnya, supporter Indonesia belum memiliki kreatifitas yang cukup baik

dunia/0/sorotan media, (di akses tanggal 2 juni 2016, pukul 01.15). 
dalam mendukung tim mereka. Namun, seiring perkembangan zaman, dan semakin canggihnya teknologi komunikasi supporter Indonesia sudah lebih kreatif dan juga lebih total dalam mendukung tim mereka. Kreatifitas dan kecintaan mereka salah satunya dipengaruhi oleh Paham yang disebut "Ultras." Ultras merupakan paham yang tengah berkembang pesat di dunia supporter. Ultras berasal dari Bahasa Latin, "Ultra" yang artinya "luar biasa," "berlebih-lebihan," dan "teramat sangat."

Ada beberapa definisi Ultras dalam dunia sepakbola. Menurut Begawan (dalam Fairush, 2013:5), Ultras dalam kelompok sepakbola digambarkan sebagai kelompok supporter yang memiliki mental keras yang sangat total dalam memberikan dukungannya pada tim kebanggaan mereka. Paham Ultras ini akhirnya berkembang hingga ke Asia Tenggara. Hal tersebut dapat dilihat dari banyaknya supporter Indonesia yang mulai menirukan gaya dukungan suporter Ultras seperti gaya berpakaian dengan menggunakan banyak atribut serba hitam dan menggunakan topi serta syal ketika datang ke stadion.

Sejak 2011, Brigta Curva Sud PSS Sleman mulai berkembang pesat. Gaya dukungan mereka pun sangatlah berbeda dengan saudara tua mereka, Slemania. Ini bisa dilihat dari warna pakaian antara Brigata Curva Sud PSS Sleman dan
Slemania. Slemania lebih condong berpakaian berwarna hijau, sedangkan Brigata Curva Sud menggunakan pakaian berwarna hitam. Tentu saja, warna hitam yang digunakan oleh Brigata Curva Sud ini merupakan ciri khas dari gaya berpakaian Ultras yang ada di Eropa. Selain pakaian, ada juga koreografi, Pyro Show, dan membentangkan banner raksasa serta penggunaan penutup wajah di setiap pertandingan yang menjadi identitas Ultras Eropa dengan Slogan "No Face No Name."Di sini, proses Mimikri terjadi.

Di era internet, bukan hal sulit untuk mendapatkan informasi tentang apapun, salah satunya tentang lagu berjudul "Forza Milan” yang banyak ditemukan di Chanelchanel youtube Ultras Italia, yang pada akhirnya ditirukan oleh Brigata Curva Sud PSS Sleman dengan mengganti kata "Forza Milan" menjadi "Forza Sleman". Ini dipermudah dengan akses film-film barat di internet. Salah satu film Ultras yang berasal dari Itali adalah L'ultimo Ultras. Film ini banyak menceritakan kehidupan seorang Ultras yang biasa melakukan tindakan di luar batas saat mendukung tim kebanggaan mereka. Seorang Ultras dapat mencintai tim kebanggannya hingga merelakan waktunya demi tim sepakbola. Dari Filmini menjadi bahan peniruan atau Mimikri yang diikuti kelompok supporter yang ada di Sleman. Kata "Brigata" pada "Brigata Curva Sud" sendiri diambil dari film L'ultimo Ultras (Andika, 2016). Secara tidak langsung, media baru atau internet 
mampu memberikan kemudahan para supporter dalam mencari paham Ultras melalui film yang pada dasarnya tidak dengan mudah ditemukan di Indonesia, dan pada akhirnya membuat Brigata Curva Sud PSS Sleman dapat menirukan apa yang mereka lihat "sebagai Ultras."

Dilihat dari sudut pandang Poskolonial, Brigata Curva Sud PSS Sleman melihat Ultras Eropa memiliki gaya yang dianggap lebih baik dan lebih hebat dibandingkan dengan gaya supporter di Indonesia. Hal ini dijelaskan oleh Bhabha dalam Gandhi (2007: 12), memori merupakan sebuah jalan yang penting dan juga kadang membahayakan antara kolonialisme dan persoalan identitas kultural. Dengan semakin berkembangnya media baru di Indonesia, akhirnya, terjadi sebuah jalan masuk untuk para supporter melakukan Mimikri dan Hibriditas dalam budaya supporter Eropa yang ditiru ke dalam budaya supporter di Indonesia. Menurut Nugroho (dalam Budiawan, 2010: 13-14), globalisasi mempunyai pengaruh yang sangat besar dalam proses penyebaran gaya ke seluruh dunia melalui penyebaran majalah, televisi, tnternet, dan media massa lainya. Youth Culture pun yang juga diikuti oleh anak muda dengan mudah diterima di berbagai belahan dunia. Selain itu, Youth Culture juga menjadi sebuah fenomena global yang pada akhirnya menyebar tanpa batas hingga masuk dalam berbagai aspek kehidupan manusia. Semakin berkembangnya fenomena Youth Culture, mengantarkan pada sebuah budaya global yang masuk tanpa disadari.

Pengaruh globalisasi pada akhirnya tidak luput juga masuk dan berkembang kedalam kultur supporter sepakbola yang ada di Indonesia. Budaya asing yang masuk melalui perkembangan globalisasi pada akhirnya membentuk satu budaya baru yang disebut sebagai Glokalisasi. Glokalisasi merupakan sebuah proses dimana terjadi bentuk penerimaan kultur asing melalui globalisasi dengan budaya lokal (Giulianotti dan Robertson, 2004). Hal ini kembali diperjelas oleh Giulianotti dan Robertson (2004) bahwa internet memegang peranan penting dalam perkembangan dunia supporter di dunia. Internet mampu memberikan satu gagasan dari setiap masing-masing kelompok supporter dalam membentuk identitas kolektif.

Pada akhirnya, dengan masuknya budaya-budaya asing melalui media baru, menghasilkan proses terbentuknya budaya baru yang datang dari budaya asing. Istilah ini disebut juga dengan Kreolisasi. Kreolisasi, menurut Tomlison (Syahputra (2016: 39), adalah terbentuknya sebuah budaya baru yang dihasilkan dari penerimaan budaya asing, tetapi tidak melepas makna asli yang terkandung di dalamnya. Dalam arti, menjadikan subidentitas tanpa makna. Berangkat dari alasan di atas, peneliti tertarik mengetahui bagaimana Mimikri, Hibriditas, Kreolisasi dalam kultur supporter sepakbola. 
Noegroho

(2010:12)

mengemukakan bahwa media baru merupakan studi tentang sebuah medium komunikasi yang terhubung dalam suatu jaringan atau media massa berbasis internet. Dalam media baru, memungkinkan terjadinya pertukaran informasi From Many To bukan lagi One Many seperti media lama, konvensional ataupun majalah. Ini telah mengubah pandangan lama tentang komunikasi dengan cara tradisional menjadi pola komunikasi yang lebih bermedia yang semakin efektif dan interaktif. Klasifikasi bisa saja terjadi perubahan adalah arus pesan mengalir dan besarnya audience, segmentatif, kemampuan dalam hal menyimpan, privasi, kontrol tentang jalannya komunikasi dan isyarat nonverbal.

Mondry juga menjelaskan (2008: 13) bahwa media baru merupakan media yang terhubung secara langsung dengan internet, media yang pada dasarnya berbasis internet, memiliki karakter fleksibel, berpotensi interaktif dan juga dapat menjadi alat pembagi informasi secara pribadi maupun secara publik.

Definisi lain mengenai media baru dikemukakan McQuail (2011: 148). Ia mengemukakan bahwa media baru merupakan perkembangan dari media lama yang memiliki ciri khas dapat berubah menjadi digitalisasi, dan datanya dapat digunakan secara pribadi atau datanya dapat disebar kepada pengguna media baru lainya sebagai alat berkomunikasi. Selain itu, terdapat satu teori tentang perkembangan media teknologi yang membentuk sebuah budaya baru yang berasal dari perkembangan teknologi yang disebut Glokalisasi. Glokalisasi, menurut Ritzer (2012: 999), merupakan konsep yang berawalkan dari budaya hibriditas budaya yang menekankan pada pengabgungan beberapa budaya yang berasal dari proses globalisasi. Hasil glokalisasi adalah sebuah budaya yang sebelumnya belum pernah ada, dan cenderung unik. Hasil budaya ini juga secara tidak langsung tidak dapat dikatakan sebagai budaya lokal maupun budaya global. Menurut Djaya (2012: 121122), glokalisasi dapat didefinisikan sebagai kemajuan global dan lokal yang membentuk suatu budaya atau hasil yang baru dan belum pernah ada diberbagai wilayah yang berbeda.

Kemajuan media baru tidak terlepas dari kemajuan globalisasi dunia. Appadurai (dalam Djay, 2012: 125-126) menjelaskan bahwa ada dua aliran teknologi global yang melatarbelakangi perkembangan globalisasi dunia. Pertama, Technoscape. Ia merupakan hubungan yang senantiasa cair yang berasal dari suatu teknologi informasi dan bersifat mekanis, yang dapat mengunduh beberapa file dan juga email yang secara terusmenerus bergerak dengan luas ke berbagai belahan dunia, dan juga menyebar dengan 
sangat cepat. Kedua, Mediascape. Ia merupakan kemampuan elektronik dalam menyebarkan informasi keseluruh dunia dengan sangat cepat, diantaranya beberapa penulis internet dan pembuatan film global dan distributor film.

\section{Mimikri dan Hibriditas dalam Kajian Poskolonial}

Kaum yang terjajah sejatinya memiliki ingatan yang cukup kuat bagi kaum yang menjajah mereka. Secara tidak sadar, perilaku kaum penjajah sudah tertanam dipikiran mereka. Kaum yang terjajah sering kali menganggap bahwa diri mereka sejajar dengan kaum penjajah. Akan tetapi, dalam sebuah peniruan identitas, kaum terjajah sering kali melakukan kesalahan dalam melakukan peniruan dan menghasilkan olok-olokan.

Ada beberapa penjelasan tentang Mimikri. Salah satunya dikemukakan oleh Bhabha (1994: 86). Ia mengatakan bahwa konsep Mimikri yang digunakan lebih menurut bahasa. Mimikri kolonial adalah sebuah rasa keinginan dari suatu subjek yang berbeda dan ingin menjadi subjek yang lain yang sama, tapi pada kenyataannya tidaklah sepenuhnya sama. Dari konsep yang sudah dilihatkan oleh Bhabha, bisa juga dikatakan bahwa pribumi atau penduduk asli ingin sekali menirukan budaya asing yang baru mereka lihat, tetapi mereka juga tidak mau menghilangkan budaya mereka karena sebagai bentuk kebanggaan dan juga rasa cinta pada budaya asli mereka.

Pada dasarnya, peniruan yang dilakukan oleh pribumi dilakukan karena melihat bahwa budaya asing terasa lebih menarik dibanding dengan budaya mereka, tetapi bukan berarti menghilangkan budaya mereka juga. Seperti dikemukakan oleh Said (dalam Sholaf, Gareth, Helen Tiffin, 2003: xxv), mimikri atau peniruan yang dilakukan memiliki tujuan yang bukan hanya ingin bisa diterima, tetapi peniruan yang dilakukan juga ingin diserap serta diadopsi. Perilaku seperti ini menyebabkan gerombolan-gerombolan terbelakang mencoba menjadikan diri mereka masuk kedalam budaya asing. Mereka menolak keaslian diri mereka dalam upaya mereka untuk bisa jauh lebih baik dari budaya asing yang telah mereka tirukan. Namun, tidak juga meninggalkan 100 persen budaya mereka

Walau banyak peniruan yang dilakukan oleh pribumi terkait budaya asing, tetapi tetap saja terdapat perbedaan yang cukup mencolok dari peniruan yang mereka lakukan. Hal ini di pertegas kembali oleh Bhaba (dalam Gandhi, 2007: 190), Mimikri Kolonial merupakan sebuah pengertian identifikasi identitas yang hampir sama dari yang mereka tirukan, akan tetapi pada kenyataan nya mereka tidak benar-benar sama. Hal ini bisa dilihat dari perbedaan yang cukup mencolok dari 
peniruan yang mereka lakukan, dan bahkan menjadi olok-olokan orang lain.

Dalam sebuah peniruan yang dilakukan kaum terjajah, sejatinya, terdapat perbedaan yang cukup mencolok. Hal ini didasari oleh perbedan kultur kaum pribumi dan juga asing. Namun pada kenyataannya, kaum terjajah malah semakin ingin membenamkan diri mereka kedalam budaya asing. Menurut Bhabha (dalam Gandhi, 2007: 190), ciri-ciri mimikri adalah ketika Barat dan jajahannya muncul menjadi sebuah kesalahan dalam menirukan apa yang mereka lihat. Mereka salah membaca bagaimana budaya asing sehingga menjadikan mereka bahan olok-olokan dari orang lain, dan juga mempermalukan diri mereka sendiri.

Pernyataan sama juga disampaikan oleh Bhabha (dalam Foulcer, 2008: 105). Menurutnya, mimikri merupakan hasil reproduksi yang belang-belang subjektivitas Eropa dalam ruang lingkup kolonial yang sudah bercampur. Hal seperti ini diakibatkan oleh pergerseran dari asal yang terkonfigurasi ulang dalam cahaya sensibiltas, dan juga dalam kegelisahan kolonialisme, dan pada akhirnya Mimikri lebih dekat kepada olokolokan. Namun dari sudut pandang lain, mimikri dapat dipandang menjadi hal yang berbeda. Seperti disampaikan oleh Bhabha (dalam Gandhi, 2007: 190), mimikri dapat menjadi sebuah senjata yang efektif dari suatu peradaban antikolosial. Bagaimana sebuah perpaduan yang ambivalen dari rasa hormat dan pemberontakan atau ketidakpatuhan. Kaum terjajah sering kali datang untuk mengamati imperatif politis dan semantik dari wacana kolonial. Namun, dalam segi waktu yang sama, kaum terjajah melakukan banyak kesalahan dalam mencangkup asumsiasumsi dari wacana ini dengan sejumlah pengetahuan yang masih belum cukup baik dan juga dengan pengetahuan mereka yang berbeda.

Kearifan budaya lokal sejatinya tidaklah tercabut sepenuhnya sampai pada akarnya, tetapi telah sedikit digabungkan arti dan juga maknanya melalui proses yang disebut sebagai hibriditas kebudayan dan identitas. Menurut Valdivina (dalam Syahputra, 2016: 36), pertemuan dan juga penggabungan kebudayaan dan identitas yang berbeda menghasilkan suatu kebudayaan dan identitas yang pernah ada dalam kultur masyarakat yang lebih dulu ada menjadi lebih tenang atau stabil, kabur, kebudayaan asli juga tidak juga hilang sepenuhnya. Proses yang terjadi pada pergabungan dari suatu kebudayaan dan juga identitas juga bisa dikenal sebagai hibriditas kebudayaan dan identitas. Selain itu, hibriditas merupakan arti yang dipakai untuk interaksi berbagai bentuk-bentuk budaya yang memiliki perbedaan yang bisa menghasilkan sebuah budaya baru dan tentu identitas baru dengan sejarah dan 
bentuk-bentuk berciri khas sendiri (Foulcher dan Tony Day, 2008: 13).

Proses hibriditas yang terjadi ini pada akhirnya mengantarkan pada sebuah proses yang biasa disebut juga dengan kreolisasi. Istilah kreolisasi menurut Tomlison (dalam Syahputra, 2016: 39) adalah proses terbentuknya budaya baru yang dihasilkan dari penerimaan budaya asing, tetapi melepas makna asli yang terkandung di dalamnya. Dalam arti besar, menjadikan subidentitas tanpa makna.

Dalam memahami proses budaya hibriditas yang telah terbentuk itu, di situlah Bhabha coba sekali lagi menjelaskannya melalui pemikirin mimikri. Menurut Bhabha (dalam Syahputra, 2016: 41-42), mimikri adalah sikap budaya yang langsung sama sekali bukan menunjukan ketergantungan dari pihak yang terjajah dengan budaya penjajah. Keduanya adalah sebuah subjek budaya. Dalam hal ini, proses peniruan yang dilakukan dengan maksud untuk menemukan kepuasan dalam sebuah makna atau tanda telah menghasilkan makna yang salah, karena dilihat tidak sesuai dan juga salah tempat. Hal ini juga memunculkan sebuah budaya baru yang yang terlihat asli padahal imitasi.

\section{Metode Penelitian}

Penelitian Mimikri Paham Ultras Melalui Media Baru "Studi Kualitatif Brigata Curva Sud PSS Sleman" ini menggunakan pendekatakan penelitian kualitatif dengan maksud untuk memahami tentang apa yang dialami oleh subjek penelitian misalnya perilaku, motivasi, tindakan, persepsi, dan lain-lain secara holistik, dan dengan cara deskripsi dalam bentuk kata-kata dan bahasa, pada suatu konteks khusus yang alamiah dan memanfaatkan berbagai metode amaliah (Moleong, 2009:6)

Penelitian ini dilakukan di bulan November-Februari 2017 di basecamp Brigata Curva Sud PSS Sleman di Condongcatur Kabupaten Slema, DIY. Stadion Maguwoharjo Sleman. Proses pengumpulan dan pengambilan data dengan teknik pemilihan narasumber menggunakanteknik purposive sampling, dimana purposive sampling merupakan teknik pengambilan sampel sumber data dengan pertimbangan tertentu. Narasumber yang dimaksud ialah salah satu pendiri Brigata Curva Sud PSS Sleman dan juga beberapa komunitas yang dianggap paling memiliki andil besar dalam kelompok.

\section{Analisis dan Pembahasan}

\section{Media Baru dan Komunitas Sebagai Pengenal Paham Ultras}

Dari lima informan kunci penelitian ini, tiga informan mengatakan bahwa mereka mengenal Paham Ultras melalui media baru. Terdapat kesamaan yang disampaikan oleh informan yang mengatakan media baru merupakan 
pengenal awal mereka kepada paham Ultras. Hal ini diungkapkan oleh informan ke-1, Fikar, dari Brigata Curva Sud PSS Sleman; informan ke-2, Alif, dari Komunitas Aliansi Utara; dan informan ke3, Deandra, dari Komunitas Campus Boys. Namun, terdapat perbedaan bentuk media baru yang digunakan dalam mengenal paham Ultras.

Perbedaan bentuk media baru yang digunakan merupakan hal yang biasa terjadi dalam pencarian sumber informasi. Informan ke-1 dan informan ke-2 menjelaskan bahwa media yang digunakan dalam mencari informasi tentang paham Ultras adalah artikel-artikel Wordpress dan juga beberapa channel Youtube. Media internet memudahkan siapa saja dalam mencari informasi tentang segala sesuatu, salah satunya dengan menggunakan Wordpress dan Youtube. Hal ini juga menunjukan sebuah sifat media baru yang dikemukakan oleh Moundry (2008: 13). Ia mengatakan bahwa media baru merupakan media yang terhubung secara langsung dengan internet, media yang pada dasarnya berbasis internet, memiliki karakteristik fleksibel, berpotensi interaktif serta dapat menjadi alat pembagi informasi secara pribadi maupun secara publik.

Tak hanya itu, masuknya paham Ultras kepada para supporter juga dapat dijelaskan oleh pemikiran Appadurai dalam Djay (2012 125-126) tentang
Technoscape yang mengatakan bahwa, "Technoscape merupakan hubungan yang senantiasa cair yang berasal dari suatu teknologi informasi dan bersifat mekanis, yang dapat bergerak seacara terus menerus dengan luas ke berbagai belahan dunia dan juga menyebar dengan sangat cepat yang dulu persebaranya tidak dapat seluas sekarang.”

Informan ke-3, Deandra, menjelaskan bahwa Facebook dengan fitur grup virtualnya akhirnya membawanya masuk ke dalam grup virtual Brigata Curva Sud PSS Sleman, ditambah dengan mudahnya mengakses Film bertemakan Ultras akhirnya semakin memperkenalkannya kepada Paham Ultras. Dari pernyataan informan ke-3, terlihat sifat media baru yang dijelaskan oleh Noegroho (2010: 12) yang menyatakan bahwa media baru memungkinkan terjadinya pertukaran informasi From many to bukan lagi One Many seperti media lama. Klasifikasi bisa terjadi perubahan adalah arus pesan mengalir beserta audience, segmentatif, serta kemampuan menyimpan pesan. Bisa dikatakan, pertukaran informasi yang dilihat informan dalam grup Facebook merupakan bahan pembelajaraan yang telah bersifat From Many to, serta dengan mudahnya mengakses Film bertemakan Ultras juga merupakan kiriman dari From Many to. 
Lain dengan informan di atas, Informan ke-4, Ozi, dari Campus Boys dan Informan ke-5, Pandu, juga dari Campus Boys menyatakan bahwa mereka mengenal paham Ultras pertama kali melalui temanteman satu komunitas. Mereka juga menjelaskan bahwa di dalam komunitas mereka terjadi saling bertukar informasi terkait paham Ultras. Akan tetapi, kedua informan juga tidak menutup kemungkinan tetap menggunakan media baru sebagai penjelas atau informasi yang memperkaya dalam mempelajari paham Ultras. Ini karena kemudahan media baru dalam mengakses informasi.

Dari paparan di atas, dapat ditarik kesimpulan bahwa peranan komunitas supporter menjadi landasan dalam mengenal paham Ultras. Namun, tidak juga meninggalkan media baru yang menjadi referensi tambahan dalam mencari informasi. Pernyataan informan ini dapat dijelaskan dari pandangan Moundry (2008: 13) yang mengatakan bahwa media baru merupakan media yang terhubung secara langsung dengan internet, media yang pada dasarnya berbasis internet, memiliki karakteristik fleksibel, berpotensi interaktif serta dapat menjadi alat pembagi informasi secara pribadi maupun secara publik. Teori ini secara jelas memperlihatkan bagaimana media baru menjadi alat pencari informasi yang cukup baik. Dengan kata lain, keberadaan media baru memberikan sumber-sumber informasi yang melimpah bagi proses 'belajar' para supporter tersebut untuk memahami paham ultras.

\section{Mimikri, Hibriditas, dan Kreolisasi Brigata Curva Sud PSS Sleman}

Pada dasarnya, peniruan yang dilakukan oleh "pribumi” dilakukan karena melihat bahwa budaya asing terasa lebih menarik dan lebih bagus dibandingkan dengan budaya mereka, tetapi bukan berarti menghilangkan budaya asli mereka secara menyeluruh. Mereka tetap mempertahankan budaya mereka, tetapi di tambahkan dengan budaya yang mereka tirukan. Seperti telah dijelaskan pada bagian sebelumnya, Ultras bukan berasal dari budaya Indonesia. Proses masuknya paham Ultras ke Indonesia menghasilkan suatu peniruan di dunia suporter Indonesia, tetapi tidak menjadikan budaya suporter lokal hilang sepenuhnya. Mereka tetap menjaga budaya lokal. Ini sebenarnya sudah dijelaskan oleh Bhabha melalui teori mimikri. Menurut Bhabha, (1994: 86), mimikri lebih daripada pengertian menurut bahasa. Mimikri kolonial adalah sebuah rasa keinginan dari suatu subjek yang sama, tetapi pada kenyataannya tidaklah sepenuhnya sama. Bahkan, dapat dikatakan berbeda dengan hal yang mereka tirukan. Berikut adalah bentukbentuk peniruan dari kelompok Brigata Curva Sud PSS Sleman beserta komunitas. 


\section{Style Supporter Ultras}

Gaya atau Style merupakan hal awal yang biasa ditirukan seseorang ketika melihat apa yang mereka tirukan. Seluruh informan dengan kompak menjelaskan bahwa mereka telah menirukan gaya atau style kelompok supporter Ultras. Informan ke-1, Fikar dari Brigata Curva Sud PSS Sleman, menjelaskan bahwa peniruan yang dilakukan mereka diambil dari kelompok supporter Ultras. Namun, Fikar juga menjelaskan bahwa mereka tetap mempertahankan budaya Indonesia khususnya budaya Jawa. Pernyataan yang dikemukakan oleh informan ini memperlihatkan bagaimana Brigata Curva Sud PSS Sleman mencoba menjadikan diri mereka sebagai kelompok Ultras dengan menirukan budaya mereka. Meskipun demikian, mereka tidak juga meninggalkan budaya asli sebagai orang Indonesia dan khususnya Jawa.

Pernyataan informan pertama ini diperkuat teori Mimikri yang telah dikemukakan Bhabha (1994: 86). Mimikri kolonial adalah sebuah rasa keinginan dari satu subjek yang berbeda menjadi subjek yang lain yang sama, tapi pada kenyataanya tidaklah sepenuhnya sama, tetapi mereka juga tidak mau meninggalkan budaya mereka sebagai bentuk kebanggaan dan juga rasa cinta pada budaya asli mereka.

Informan ke-2, Alif dari Aliansi Utara, Informan ke-3, Deandra dari
Campus Boys, dan Informan ke-5, Pandu dari Campus Boys, mengatakan bahwa pada zamannya mereka pernah menggunakan gaya yang sangat identik dengan kelompok Ultras dengan menggunakan pakaian tebal atau parka. Informan ke-2 juga menambahkan alasan memakai pakaian tebal atau parka bukan dikarenakan cuaca, tapi lebih ke passion dan ingin menunjukkan jati dirinya sebagai Ultras. Perbedaan budaya dan juga cuaca antara Eropa dan Indonesia, akan membuat mereka justru terlihat aneh dan tidak biasa, yang akan membuat mereka menjadi bahan olok-olokan dari supporter lain. Fenomena supporter Ultras ini dapat dilihat dari teori Mimikri yang di jelaskan oleh Bhabha dalam Gandhi (2007: 190), bahwa ciri-ciri Mimikri adalah ketika Barat dan jajahannya muncul menjadi sebuah kesalahan dalam menirukan apa yang mereka lihat. Mereka salah membaca bagaimana budaya asing sehingga menjadikan mereka bahan olok-olokan dari orang lain, dan juga mempermalukan diri mereka sendiri. Olok-olokan yang diberikan bukan lagi tanpa alasan, olokolokan diberikan karena informan mencoba mengikuti budaya asing, tapi peniruan yang dilakukan tidak melihat bagaimana cuaca dan juga kultur yang ada di masyarakat.

Informan ke-4, Ozi dari Campus Boys, memiliki alasan tersendiri melakukan peniruan gaya kelompok Ultras. Informan menjelaskan bahwa 
pakaian Casual karena gaya ini cukup berbeda dengan gaya supporter lokal, dan juga sebagai cara untuk menghormati tim yang dibela. Memperhatikan pernyataan informan ini, dapat dikaitkan dengan teori yang dikemukakan oleh Said dalam Sholaf, Gareth, Helen Tiffin (2003: xxv). Menurutnya, mimikri atau peniruan yang dilakukan memiliki tujuan yang bukan hanya ingin bisa diterima, tetapi juga ingin diserap serta diadopsi. Perilaku ini menyebabkan gerombolan-gerombolan terbelakang yang berusaha menjadikan diri mereka masuk ke dalam budaya asing. Mereka menolak keaslian diri mereka dalam upaya mereka untuk bisa jauh lebih baik dari apa yang mereka tirukan. Teori ini memperlihatkan bagaimana Informan mencoba menjadikan dirinya berbeda dengan kelompok asli mereka, dan mencoba menjadikan dirinya tenggelam dalam budaya asing.

\section{Peniruan Koreografi Kelompok Supporter Ultras}

Supporter sepakbola di Indonesia telah dicap sebagai kelompok perusuh dan pembuat onar. Namun, saat ini, cap masyarakat tersebut sudah sedikit mulai berubah dengan hadirnya kelompok Brigata Curva Sud PSS Sleman yang menunjukkan kreatifitas mereka lewat koreografi. Proses koreografi yang dilakukan oleh Brigata Curva Sud PSS Sleman tidak terlepas dari peniruan kelompok supporter Ultras. Informan ke-1, Fikar dari Brigata Curva Sud PSS Sleman dan informan ke-5 Pandu dari Campus Boys, menjelaskan bahwa koreografi yang banyak dibuat diambil dari kelompok supporter Ultras di Itali. Mereka juga mengatakan bahwa perlu proses yang panjang sehingga dapat membuat koreografi yang indah. Meskipun demikian, terdapat satu koreografi yang membuat mereka menjadikannya dicap tidak menunjukkan rasa nasionalisme, yakni koreografi yang menirukan supporter Juventus. 


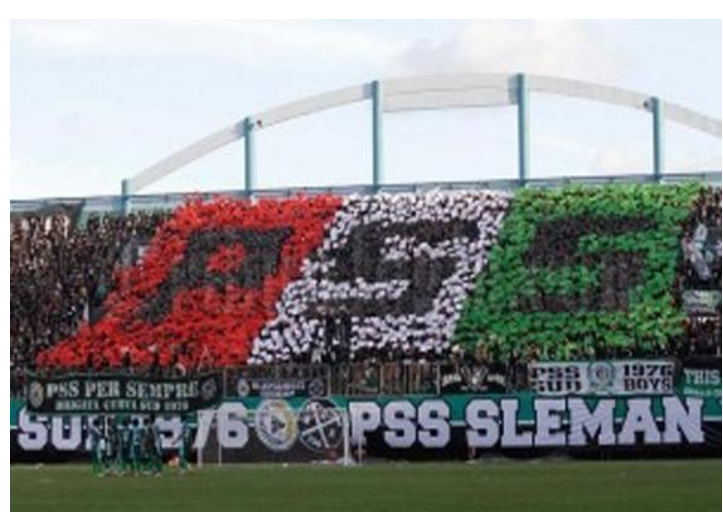

Koreografi yang dilakukan oleh kelompok Brigata Curva Sud PSS Sleman di atas memperlihatkan bagaimana hasil dari pernyataan yang dikemukakan oleh informan ke-1, Fikar, yang menyebutkan bahwa koreografi merupakan proses peniruan dari kelompok supporter Ultras. Namun, terdapat satu koreografi yang justru akan berakibat mendapatkan olokolokan dari supporter lain karena dianggap tidak menunjukan rasa nasionalisme dengan lebih memilih menggunakan warna bendera Itali dibandingkan dengan bendera Indonesia.

Brigata Curva Sud PSS Sleman terlihat jelas mencoba menjadikan diri mereka sama seperti kelompok Ultras Italia dengan menggunakan warna bendera Italia dalam koreografi mereka. Fenomena ini kembali dapat dijelaskan melalui teori Mimikri yang diutarakan oleh dari Bhabha dalam Gandhi (2007: 1990). Dalam hal ini, mimikri merupakan sebuah pengertian dari identifikasi yang hampir

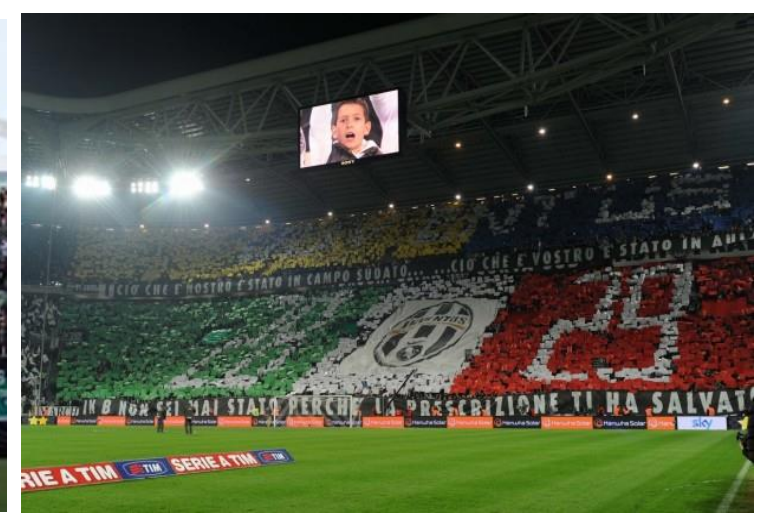

sama dari yang mereka tirukan, tetapi pada kenyataannya tidak benar-benar sama. Hal ini dapat menjadikan mereka bahan pembicaraan supporter lain karena dianggap tidak membawa kultur asli supporter Indonesia.

\section{Chant Supporter Ultras}

Setiap kelompok supporter sepakbola di dunia pasti memiliki ciri khas sendiri untuk nyanyian atau Chant yang mereka gunakan dalam mendukung tim. Salah satunya adalah Brigata Curva Sud PSS Sleman. Brigata Curva Sud PSS Sleman merupakan kelompok supporter yang memiliki ciri khas nyanyian ketika mendukung tim. Namun, terdapat peniruan yang dilakukan dalam memberikan dukungan ketika kepada tim dalam bentuk nyanyian atau Chant. Menurut narasumber ke-1, Fikar dari Brigata Curva Sud PSS Sleman dan narasumber ke-5 Pandu dari komunitas Campus Boys, mengatakan bahwa cukup 
banyak peniruan chant-chant yang berasal dari Italia yang diambil dan diubah menjadi chant-chant lokal. Sebagai contoh, chant milik Ultras AC Milan "Forza Milan" yang diubah menjadi "Forza Sleman".

Hal ini memperlihatkan bagaimana Brigata Curva Sud PSS Sleman mencoba menjadikan dirinya sama dengan Ultras AC Milan dengan menirukan chant mereka. Namun, pada kenyataannya, peniruan yang dilakukan sejatinya tidak akan pernah sama karena perbedaan kultur dan aksen yang tidak akan bisa dipelajari dengan mudah. Fenomen ini dapat dikaitkan kembali dengan teori Mimikri dari Bhaba dalam bahwa Mimikri Kolonial merupakan sebuah pengertian dari identifikasi identitas yang hampir sama dari yang mereka tirukan, tetapi tidak benar-benar sama. Hal ini bisa dilihat dari perbedaan yang cukup mencolok dari peniruan yang mereka lakukan, dan bahkan menjadi olok-olokan orang lain

\section{Peniruan Pemakaian Hoodie dan} Penutup Wajah Kelompok

\section{Supporer Ultras}

Perkembangan atribut Hoodie dan penutup wajah akhirnya berkembang di kalangan kelompok supporter yang ada di Indonesia. Dari informan ke-1 yang menyatakan bahwa terdapat perbedaan makna yang digunakan oleh kelompok supporetr Ultras Eropa dengan kelompok Brigata Curva Sud PSS Sleman tentang pemakaian Hoodie. Informan ke-1, Fikar, mengatakan bahwa Brigata Curva Sud cenderung menggunakan Hoodie hanya untuk pertandingan malam dan perbedaan suhu juga membuat Hoodie tak dapat digunakan sepenuhnya sama. Dalam hal ini, mimikri dapat menjadi sebuah senjata yang efektif dari sebuah peradaban antikolosial, bagaimana sebuah perpaduan yang ambivalen dari rasa hormat dan pemberontakan atau ketidak patuhan. Kaum terjajah sering kali datang untuk mengamati imperatif politis dan semantik dari wacana kolonial. Namun, dalam segi waktu yang sama, kaum terjajah melakukan banyak kesalahan dalam mencangkup asumsi-asumsi dari wacana ini dengan sejumlah pengetahuan yang masih belum cukup baik dan juga dengan pengetahuan mereka yang berbeda.

\section{Budaya Baru Wall Of Dead dalam Sepakbola}

Perkembangan budaya baru dalam Brigata Curva Sud PSS Sleman akhirnya mengantarkan mereka pada Hibriditas. Menurut Valdivina (Syahputra, 2016: 36) pertemuan dan juga penggabungan kebudayaan dan identitas yang berbeda menghasilkan suatu kebudayaan dan identitas yang pernah ada dalam kultur masyarakat yang lebih dulu ada menjadi lebih tenang atau stabil, kabur, kebudayaan asli juga tidak juga hilang sepenuhnya. 
Pada akhirnya, terbentuknya sebuah identitas baru yang mengantarkan pada sebuah proses Kreolasi. Menurut Tomlison (Syahputra, 2016: 39), proses kreolasi ini terjadi seperti proses membentuknya budaya baru yang dihasilkan dari penerimaan budaya asing akan tetapi melepas makna asli dari yang terkandung di dalamnya. Dalam arti, yang besar menjadikan sub identitas tanpa makna. Proses Kreolisasi di sini diperlihatkan dengan terbentuknya satu budaya baru yang belum pernah ada di dunia yaitu aksi wall of dead dalam tribun sepakbola di Indonesia.

Dari sudut pandang lain, semakin dekat para supporter dengan teknologi akhirnya membentuk sebuah budaya baru yang berasal dari perkembangan teknologi yang disebut Glokalisasi. Glokalisasi, menurut Ritzer (2012: 999), glokalisasi merupakan konsep yang berawalkan dari budaya hibriditas yang menekankan pada penggabungan beberapa budaya yang berasal dari proses globalisasi. Hasil glokalisasi membuat sebuah budaya yang sebelumnya belum pernah ada dan cenderung unik. Hasil budaya ini juga tidak dapat dikatakan sebagai budaya lokal maupun budaya global. Dalam arti, teknologi mengantarkan sebuah budaya baru yang akhirnya bergabung dengan budaya lokal.

\section{Warna Hitam-Hitam Kelompok Supporter Ultras}

Perkembangan warna hitam pada akhirnya berkembang juga dikalangan kelompok supporter yang ada di Indonesia. Kelompok supporter Indonesia yang saat ini memakai warna hitam-hitam adalah kelompok supporter Brigata Curva Sud PSS Sleman. Informan ke-1 dan informan ke-2 menjelaskan bahwa peniruan yang mereka lakukan adalah dengan menggunakan warna hitam-hitam baik dalam style maupun dalam atribut mereka.

Informan ke-1, Fikar dari Brigata Curva Sud PSS Sleman, mengatakan bahwa peniruan yang dilakukan sebenarnya bukanlah sebuah kesengajaan, akan tetapi berawal dari rasa bosan para supporter dalam menggunakan warna hijau yang identik dengan warna PSS Sleman. Pada 2011, Band metal sendiri juga tengah berkembang di kalangan para supporter.

Dari alasan yang dikeluarkan oleh informan di atas, dapat disimpulkan telah terjadi hibriditas yang dibentuk dari bergabungnya kultur penggemar musik Hardocre dengan kultur supporter Indonesia yang membentuk sebuah identitas baru bahwa kelompok supporter Indonesia tidak harus memakai warna yang sama dengan tim yang dibela. Proses hibriditas kembali dapat dikaitkan dengan teori dari Foulcher dan Tony day (2008: 
13). Hibriditas merupakan arti yang dipakai untuk interaksi berbagai bentukbentuk budaya yang memiliki perbedaan yang bisa menghasilkan sebuah budaya baru, dan tentu identitas baru dengan sejarah dan bentuk-bentuk berciri khas sendiri.

\section{Peniruan Corteo Supporter Ultras}

Corteo merupakan salah satu aksi yang kerap digunakan oleh kelompok supporter Ultras. Aksi Corteo merupakan salah satu cara memberikan dukungan kepada tim, dan juga dapat menjatuhkan mental supporter lawan yang datang untuk melihat pertandingan.

Perkembangan Corteo saat ini juga tengah masuk di kalangan supporter yang ada di Indonesia. Kelompok supporter yang melakukan aksi Corteo tersebut adalah komunitas Campus Boys yang merupakan bagian dari kelompok supporter Brigata Curva Sud PSS Sleman. Informan ke-5, Pandu dari komunitas Campus Boys, aksi Corteo yang dilakukan adalah hasil dari peniruan kelompok supporter Ultras. Peniruan yang dilakukan Campus Boys ternyata tidak sepenuhnya berhasil dan juga sama dengan kelompok supporter Ultras. Aksi Corteo pada kenyataannya belum bisa dilakukan dalam kultur supporter Indonesia. Salah satu kesalahan peniruan Campus Boys adalah tidak memperhatikan kondisi jalan menuju stadion yang akan terkena dampak kemacetan jika supporter melakukan aksi Corteo.

Walau sekilas aksi yang dilakukan oleh Campus Boys terlihat sama dengan aksi yang dilakukan oleh kelompok supporter Ultras, akan tetapi tetap saja dapat terlihat perbedaan yang cukup mencolok diantara mereka.

\section{Penutup}

Proses pembelajaraan yang dilakukan oleh kelompok suporter Brigata Curva Sud PSS Sleman terbagai menjadi 2 cara. Pertama, media baru mampu menjadi media yang dapat mengenalkan paham Ultras kepada para supporter dengan berbagai sifatnya yang memudahkan siapapun dalam mencari informasi, dan juga beberapa fiturnya seperti media sosial. Kedua, komunitas supporter juga mampu menjadi awal pengenal para supporter dalam mengenal paham Ultras, akan tetapi pada kenyataannya para supporter tetaplah memerlukan media baru sebagai alat untuk memperdalam pemahaman mereka tentang paham Ultras.

Proses peniruan yang dilakukan kelompok Brigata Curva Sud PSS Sleman dapat dibagi menjadi beberapa kategori. Pertama, peniruan dalam bentuk Mimikri. Mimikri merupakan sebuah pengertian proses peniruan yang dilakukan untuk menjadikan dirinya sebagai pihak yang ditiru. Pada kenyataannya, terdapat berbagai kesalahan yang membuat mereka 
akhirnya mendapatkan olok-olokan dari orang lain. Hal ini serupa dengan peniruan yang dilakukan oleh kelompok Brigata Curva Sud PSS Sleman yang ternyata dalam peniruannya terdapat kesalahan pemahaman makna dan situasi yang membuat mereka menjadi bahan olokolokan dari supporter lain.

Kedua, peniruan yang dilakukan dengan cara menggabungkan satu kultur dengan kultur lainnya atau yang disebut hibriditas. Hibriditas yang dilakukan oleh kelompok supporter Brigata Curva Sud PSS Sleman adalah dengan menggabungkan kultur supporter sepakbola dengan kultur suppoter sepakbola lokal dengan supporter Ultras. Selain itu, juga menggabungkan penggemar dari band-band beraliran
Metal dan Hardcore, yang pada akhirnya melahirkan satu identitas baru dalam dunia supporter sepakbola di dunia yang bisa disebut juga dengan nama Sleman Football Hardcore sebagai kultur baru yang lahir

Ketiga, adalah sebuah pembentukan budaya baru yang dihasilkan dari penerimaan budaya baru yang dihasilkan dari penerimaan budaya asing. Proses ini disebut juga dengan kreolisasi. Kreolisai yang dilakukan Brigata Curva Sud PSS Sleman akhirnya menghasilkan satu budaya baru yang dahulu belum pernah ada, budaya baru ini sendiri lahir dari proses penerimaan budaya asing akan tetapi tidak melepas makna asli didalamnya.

\section{DAFTAR PUSTAKA}

\section{Buku}

Syahputra, Iswandi. (2016). Pemuja Sepakbola. Jakarta: Kepustakaan Populer Gramedia.

Gifary dan Kurnia. (2015). "Intensitas pengguna smartphone terhadap perilaku komunikasi”, Jurnal Sosioteknologi, Vol, 14 (Agustus 2015), 170-178.
Handoko, Anung. (2008). Sepakbola Tanpa Batas. Yogyakarta: Kanisius. Mondry. (2008). PemahamanTeori dan Praktik Jurnalistik. Bogor: Ghalia Indonesia.

Noegroho. (2010). Teknologi Komunikasi. Graha Ilmu: Yogyakarta.

Nurudin. (2007). Pengantar Komunikasi Massa. Jakarta: Grafindo Persada. 
Rakmat Jalaludin. (2005). "Psikologi Komunikasi”. Bandung: Remaja Rosdakarya.

Ashcroft, Gareth Griffiths, Helen Tiffin. (2003). Menelanjangi Kuasa Bahasa. Yogyakarta: Qalam.

Day, Tony dan Keith Foulcher. Sastra Indonesia Modern Kritik Postkolonial. Edisi Revisi. Jakarta: Yayasan Obor Indonesia.

Budiawan. (2010). Ambivalensi: Postkolonialisme membedah musik sampai agama di Indonesia. Yogyakarta: Jalasutra.

Creswell, John W. (2008) Education Research. Planing, Conducting, and Evaluating Qualitative \& Quantitative Approaches. London. Sage Publications.

Gay, L.R, G.E. Mills. (2006). Educational Research (Competencies For Analysis and Applications). USA: Pearson.

Kriyantono, Rachmat. (2006). Teknis Praktis Riset Komunikasi. Jakarta: Kenca Prenada Media Group.

Moleong, Lexy J. (1990). Metodologi Penelitian Kualitatif. Bandung: PT Remaja Rosdakarya.

Sugiyono. (2012). Metode Penelitian Kuantitatif, Kualitatif, dan R\&D. Bandung: Alfabeta.
Bhabha, Homi K. (1994). Location of Culture. New York: Routledge.

Gandhi, Leela. (2007). Teori Poskolonial: Upaya Meruntuhkan Hegemoni Barat, Terj. Yuwan Wahyuni dan Nur Hamidah. Yogyakarta: Qalam. Junaedi, Fajar. 2012. Bonek : Komunitas Suporter Pertama dan Terbesar di Indonesia. Yogyakarta : Mata Padi Pressindo.

Miles, Matthew dan Huberman, A. Michael. 1992. Analisis Data Kualitatif: Buku Sumber Tantang Metode-Metode Baru. Jakarta:UI Press.

\section{Jurnal}

Kumar, S. (2011). “Bhaba's Notion Of 'Mimicry'and 'Ambivalance'In V.S Naipaul's A Bend In The River', Jurnal Of Arts, Science \& Commerce, Vol. II, (Oktober 2011), Hal 118-122).

Gifary dan Kurnia. (2015). "Intensitas pengguna smartphone terhadap perilaku komunikasi”, Jurnal Sosioteknologi, Vol, 14 (Agustus 2015), 170-178.

Pramiyanti, Putri dan Nuraeni. (2014). "Motif dalam menggunakan media baru (Studi pada remaja di daerah sub-urban kota Bandung”, Jurnal KomuniTi, Vol. VI, (September 2014), Hal 95-103.

Setyawan, R. (2013). "Kekuatan New Media dalam membentuk Budaya Populer di Indonesia", eJurnal Ilmu Komunikasi, Vol. 1 (2013), Hal 355374

Giulianotti, R. Dan R. Robertson. (2004). "The Globalization of Football: A Study in the Glocalization of the 'Serius Life". The British Journal of Sociology.55(4): 545-568. 
Artawan Dan Yasa. (2015). "Mimikri Dan Stereotipe Kolonial Terhadap Budak Dalam Novel-novel Balai Pustaka”, Jurnal Ilmu Sosial dan Humaniora. Vol. 4 (2015), Hal 577584 .

Nugroho, Boy (2010). "Se-rambut tak semusik", dalam Ambivalensi "postkolonialisme membedah musik sampai agama di Indonesia, ed. Budiawan. Yogyakarta : Penerbit Jalasutra

Komalasari, Sandria (2010). "Indorock (Musik hibrid dan secelah ruang yang nyaris terlupakan)", dalam Ambivalensi "post-kolonialisme membedah musik sampai agama di Indonesia, ed. Budiawan. Yogyakarta : Penerbit Jalasutra

\section{Internet}

Fairush, "Persepsi aremania terhadap paham ultras"

http://www.academia.edu/457490 4/persepsi aremania terhadap $p$ aham ultras diakses 2 juni 2016, ( di akses tanggal 2 desember 2016, pukul 09.35)

Al Afghani Gilang Andika, "Brigata Curva Sud: Wajah Suporter Progresif di Indonesia", http://fandom.id/feature/kultur/2 016/11/brigata-curva-sud-wajahsuporter-progresif-di-indonesia/,,( di akses tanggal 2 desember 2016, pukul 14.00) https://kominfo.go.id/content/detail/428 6/pengguna-internet-indonesianomor-enamdunia/o/sorotan media, (di akses tanggal 2 juni 2016, pukul 01.15 ).

https://www.dreamstime.com/photosimages/AC-milan-ultras.html. . (di akses tanggal 27 Februari 2017, pukul 20.00).

http://panditfootball.com/cerita/97314/ $\underline{R D K / 140603 / h o o l i g a n s-i n g g r i s-}$ dan-argentina-siap-tempur-dibrasil. .(di akses tanggal 27

Februari 2017, pukul 21.00).

http://beyondthefieldofplay.com/category _serie-a-the-ultras/. . (di akses tanggal 27 Februari 2017, pukul 21.00).

http://simple- $x-$

blog.blogspot.co.id/2015/o1/19klub-sepakbola-eropa-.(di akses tanggal 29 Februari 2017, pukul 23.00).

https://www.pinterest.com/pin/1375005 94851143375/. . (di akses tanggal 29 Februari 2017, pukul 23.00) 
Jurnal komunikasi, Volume 11, Nomor 2, April 2017 